Journal of Engineering and Applied Sciences 14 (18): 6876-6884, 2019

ISSN: 1816-949X

(C) Medwell Journals, 2019

\title{
Development of Information and Control System for Road Vehicles Near Level Crossing
}

\author{
Ashish Kumar Aman and Amit Kumar \\ Department of Mechanical Engineering, National Institution of Technology Patna, \\ Ashok Rajpath, 800005 Patna, India, ashish.amanbgp@gmail.com
}

\begin{abstract}
The safety issues at the level crossings are of prime concern in most of the countries as the economic progression has led to swelling of infrastructure related to transportation. With such advancements, the rate of accidents and fatalities at the level crossings have also increased. The study offers a broad appraisal of the prevailing strategies implemented for improving the security and safety at the level crossings. The study also deliberated the Indian scenario in particular. A case study pertaining to the level crossing in the eastern part of India was deliberated and the consequence of staffing the level crossing was studied. The study concluded that the manned level crossing leads to congestion in road traffic due to high communication time and barrier closure time. Therefore, it is better to adopt automation-based barrier functioning at the level crossings. A comparative study of the prevalent worldwide techniques used for safety at level crossings are also discussed in the study. The study concludes with the discussion on the proposed conceptual framework of the methodology which may be employed to improve the safety scenario at the level crossings.
\end{abstract}

Key words: Level crossings, safety, technology based systems, anthropological issue, indian case study, sensor based safety system

\section{INTRODUCTION}

The rail system is more apposite to a developing economy like India because of the low costs of transport. The importance of the rail network in the socio-economic parlance cannot be undermined. This communicates amongst all the social aspects. The railways play an imperative role in the integration of markets and the upsurge of trade. With the increase in population, the demand for rail and rail traffic is increasing rapidly. However, one of the focal issues in railway system is safety concerns. The safety in the rail system comprises of the track safety, passenger safety, interlocking safety etc. However, one of the major concerns is the safety at the railroad crossings. The place where the railroad tracks and roads intersect at the same level is called "Cross Level" or level crossing (Anonymous, 2012).

Accidents at railway crossings became a serious concern throughout the globe. In the past decades, the railways have developed by leaps and bounds technologically. However, the development in the expertise involved in the safety of railway system is not in accord with technological development of the railways. Besides this, even though some state of the art methods for safety are available but their use is limited. The scenario is more or less same globally. The steady growth in the population density around the railway tracks have compounded the problems of safety. Indian railways in particular rely heavily on the age old manual methods of safety at the level crossings. In India, old and mechanical type of level, crossings are prevalent. Existing railways gate control system typically are of two types-namely the manned and unmanned gates at different locations. Bulk of them are unmanned. It is reported in daily newspapers that numerous rail accidents happen at unmanned railway crossings. This is largely because of the negligence in operations or deficiency of workforces. Hence, the present scenario of the level crossings control system is highly inefficient and is not at all appropriate for stopping the ever-rising toll on railway gate trespassing events commendably. At most, places the manual safety system encompasses a pulley-based system, whereby the barrier is lowered on the advent of any train and stops the passengers to cross across the tracks.

In the global parlance, the safety at railway level crossings is increasingly attracting the attention of the concerned authorities and the stakeholder's, i.e., the railways and the community residing nearby. Due to high economical stakes involved in the collisions, the

Corresponding Author: Ashish Kumar Aman, Department of Mechanical Engineering, National Institution of Technology Patna, Ashok Rajpath, 800005 Patna, India, ashish.amanbgp@gmail.com 
government agencies and the concerned parties are holding nothing back in developing a system that improves the safety at the level crossings. These measures are quite substantial yielding better results but are not cost effective.

The current study provides an in depth survey of the prevalent safety scenario throughout the world. An extensive review of the latest safety measures taken in different countries are discussed along with their chronological development. A case study from the Indian railway system has been deliberated to understand the actual issues of concern in context of safety at the level crossings. The study also, provides an in-depth comparative investigation of the different technologies involved in the improvement of the safety scenario at the level crossings. A conceptual framework of the plausible solution for the shortcomings of the current prevalent system has also been discoursed in the study.

\section{REASONS FOR MISHAPS AT LEVEL CROSSINGS}

The current section delves into the details pertaining to the relevant causes and modes of the mishaps at the level crossings. The generic causes of the accidents may be enumerated as follows (Tey et al., 2011):

- The ever-increasing crossings due to rapid infrastructural developments throughout the world

- Trains cannot be rendered motionless easily as is the case with road vehicles

- The locomotive pilots may spot the vehicle but the time to react for stopping the train is miniscule

- The accidents may take place due to driver's misjudgment even, if the time to react to the situation is sufficient

\section{THE CURRENT GLOBAL SCENARIO}

The safety issues at the level crossings has led to the engagement of several researchers to for providing the plausible solutions across the world. The major issue related to the issue is that the nature and magnitude of the issue related to safety at the level crossings is highly affected by the local parameters, i.e., they are country or location specific. Therefore, the methodology adopted to counter such menace may not be generic in nature. Nevertheless, the countermeasure at one location may serve as inspiration for solving the problem at other locations. The current section presents a comprehensive survey of the methodologies used worldwide to tackle the problem related to safety at level crossings.
There is no dearth of researchers who researchers who are working to devise new strategies for improving the safety at the level crossings. A magnetic sensor based railway gate automation system has been designed by Xishi et al. (1992) which successfully reduced the rate of accidents and fatalities. OGSi and JESS based technology was implemented by Jeong et al. (2008) for reduction of level crossing based mishaps. A comprehensive discussion of the various methods employed by the researchers at the global level is presented by Dewangan et al. (2012).

In previous study, various aspects of problem related to level crossing were studied. In words to be acquainted with the present condition of the problem, various articles available were studied. The succeeding subsection give a brief insight into the literature studied. Several researchers performed commendable research dealing with the issues related to the security at level crossings (Larue et al., 2018; Larue and Wullems, 2017; Fries and Shields, 2018). Most of the efforts in this direction involved the usage of micro-controllers (Anjali and Geetha, 2017; Li et al., 2017). Punekar and Raut (2013) devised an obstacle detection system using GPS-GSM model. Chouhan (2014) put forward an anti-collision system using digital lens sensors. Controllers based on the Zigbee was used by Sreelakshmi et al. (2017) whereas (Kumar and Singh, 2014) deployed a collision detection technology using robots working on AVR hardware. Pattanaik and Yadav (2015) put forward a fuzzy logic based system. Wireless network was used by Lakshmi and Kumar (2015) to propose an accident detection system.

The various methodologies employed by the researchers to deal with the issue of level crossing safety may be broadly studied under following heads as shown in Fig. 1.

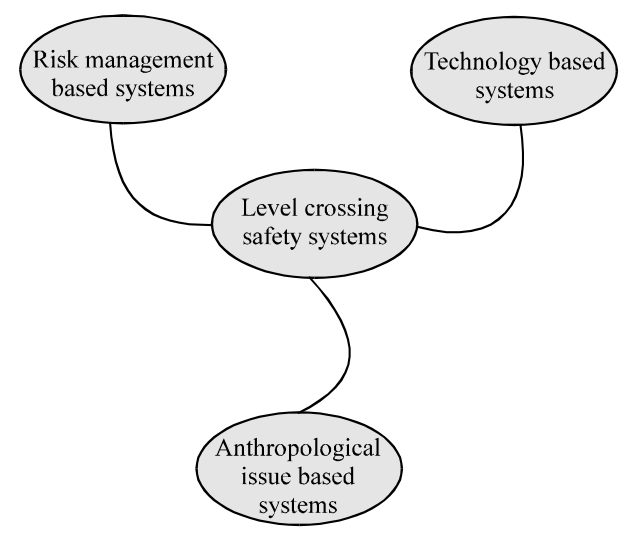

Fig. 1: Broad classification of the level crossing safety strategies 
- Technology based systems

- Anthropological issue based systems

- Risk management based systems

Technology based systems: The advent of the 21st century has led to development of innovative avenues in the domain of technology in general and inter-disciplinary application of the developed technologies in particular. In accord with the modern trend, the latest technologies also find their application in the safety parlance at the level crossings. Several researchers proposed new technologies or application of the latest technologies in the said domain.

Radio Frequency Identification system (RFID) based identification system was used by several researchers to design an identification system for railway tracks. Micro-controller based RFID tag and reader were used to sense advent of train on the track leading to automatic control of the LC gates. This system led to reduction of the mishaps at the crossings via. better railway traffic management (Jadhav et al., 2017; Masek et al., 2016).

The infrared sensors were employed by some of the researchers to detect the surrounding characteristics at the level crossings. The infrared radiations are capable of detecting objects as well as its motion. The same was engaged in detecting the presence of trains at the level crossings. A cluster of sensors at the level crossings enabled the estimation of exact location and the speed of the train along with its direction of motion. This information may be utilised for the operation of the security barriers at the level crossings (Potdar et al., 2017; Garcia-Dominguez et al., 2008; Larue et al., 2015).

In some areas of the globe, the manual systems are also prevalent for the opening and closing of the security gates. These manual barriers may be open or close depending upon the conditions. On busy roads, they are generally open and are manually closed on the arrival of the train whereas at the quitter roads they are generally closed and are occasionally opened. The reaction time for prevention of mishaps is very low at these crossings making it unsuitable for high-speed train traffic Marquez et al., 2015).

Control of railway level-crossing gate through an android application may be performed by the driver or the station master. The persons with lesser technical knowhow devise a graphic user interface for the said systems for making it operable (Mapari et al., 2016). Sometimes, Bluetooth device is interfaced with this system to achieve remote operation. The motors controlling the opening and closing of the security gate, a micro controller based motor driver is employed (Pwint et al., 2014).
The research in the direction of gateless level crossing has also gained momentum. An attempt to devise a system producing warning signs in terms of hooters and flashing lights informing the road users about the impending risk in crossing the level crossings were also made by some researchers. The warning signals also, serve as a deterrence for the locomotive drivers to remain vigilant and control the speed of the train prior to the level crossings.

LIDAR (Laser Image Detection and Ranging) operates via. emission and reception of the laser rhythms that are echoed off the objects. The echoed back laser rhythms are employed to decide the direction of movement of the object. The period of laser rhythms release and reception forms the basis of distance estimation pertaining to the object. This information may be used to operate the security barrier may be used (Kim et al., 2012; Govoni et al., 2015; Kim et al., 2014; Tastimur et al., 2017; Da Costa and Pereira, 2018).

The system involves detection and tracking integrated together by Punekar and Raut. The system utilised GSM and GPS technologies which gives up-to-date information about the ongoing operation. The system real time surveillance served as a deterrence to prevent accident at level crossing via early warning to train operators.

Anthropological issue based systems: For any security, system to work efficiently the human interface must be perfect. Human beings also form the frailest $\operatorname{cog}$ in the wheel of the safety system. This is evident from the studies which reveal that the failure of the safety systems due to human negligence is much higher than the failure of any other component of the system. Hence, the focus of the study must also be towards the behaviour and attitude of the human beings who are a component of the installed safety system. Recently, the Australians (Kumar and Sinha, 2008) understood the significance of the human element in the system, performed the study for it and suggested remedies for improvement of the human attitude when it is a part of the system.

The study of the behaviour of the human beings in general and the road users in particular warrants the development of efficient models using all the criteria which define the working efficiency of the human beings. In other words, the psychological parameters concerning the persons driving the vehicle viz. insight, reasoning, alertness, attentiveness, lethargy, capability, etc., must be embedded into the model developed for the study of human behaviour. Some of the parameters that must be considered while development of an anthropological model are enumerated as follows: 
- The character of the driver using the road vehicle, his driving intentions and sentiments while driving

- The drivers conscious while taking risk

- The interaction between the human characteristics and the environmental characteristics in which the driver is working amidst the region which is prone to accidents

- The workload and additional benefits for the driver to research in risk prone environment

The anthropological behaviour of the human elements is also a function of the frequent use of the area, age and the measured approach of the drivers. The failure of perfect judgement is also one of the prime causes of the failure of human errors.

Risk management based systems: The study surveyed under the category of risk management based systems present the overall policy based measures taken by different authorities in different parts of the world. The current subsection delves into the policies and the strategies adopted by the authorised agencies to ensure safety in different countries of the world.

The Australian government used Australian Level Crossing Assessment Model (ALCAM) to assess the hazards at the level crossings. A mathematical tool considers incident history, engineering experience, local knowledge of driver or pedestrian behaviour, social and economic assessment and standards and international best practices to estimate the degree of danger at the level crossings. It must be noted that such a model cannot be used in isolation as a preventive model but serves as a base for designing other safety models (Nelson-Furnell, 2012).

The Canadian authorities developed a regression based collision prediction model that uses the road length and the traffic volume for estimation of the collision probability. However, later it was discovered that the linear regression based model lacked distributional properties to describe the collision scenario effectively. To overcome such short comings a generalized linear regression model was devised to predict the collision probability.

A model developed by the Department of Transportation in united states facilitated prediction of collisions at highway-rail grade crossings (Farr, 1987). The said model was fundamentally composed of a statistical model for estimating the projected number of collisions in a calendar year, a quasi-Bayesian fine-tuning to combine chronological accident annotations at specific crossings and a peripheral adjustment factor to account for various types of warning device. The warning devices mostly incorporated in the system included signs only (type S), signs+flashing lights (type F) and signs+flashing lights+gates (type G).

The All Level Crossing Risk Model (ALCRM) employed by the Irish government is a web based risk management tool which takes into account the risk related to the users, passengers and the rail staff to pin point the level crossings which requires higher priority while installation of safety devices. The model is intended to evaluate individual risk, collective risk and potential operational costs at each crossing to facilitate cost-efficient analysis for new operation scenarios, mitigation measures and upgrades (Liu et al., 2017).

The Japanese authorities used an obstacle detection system at critical junctures to assess the risk of collisions. All the key automatic level crossings in Japan are furnished with obstacle-detecting systems to avert fatal accidents. When the obstacle-detecting system detects objects, it stops the approaching trains by controlling signals. The obstacle-detection systems are classified into three types viz the light-interrupting type, the induction loop type and the ultrasonic type (Anandarao and Martland, 1998).

The Spanish agencies worked on the Failure Modes and Effects Analysis (FMEA) based model for a systematic analysis of the involved technique and isolate the possible modes of fiascos, their root causes and their effects on the system performance.

In Indonesian, all level crossings are automated using sirens in place of conventional bells. Hong Kong makes use of the underground railway network or elevated overpass to prevent collisions at level crossings, i.e., usage of automated level crossing is very limited in Hong Kong.

A case study for indian scenario: The Indian Railways in the recent years have decided to do away with the unmanned level crossings in phased manner. The focus of the Indian Railways is on converting the unmanned level crossings to the manned level crossings. It has emerged from the analysis of pattern of accidents that staffing of unmanned level crossing is not an ideal solution.

In order to have a first-hand experience about the prevailing scenario at the manned level crossings in India a survey was conducted at a level crossing in the eastern part of India and the data pertaining to it were collected for a period of ten days (Fig. 2 and 3). The summary of the data is depicted in Table 1.

It is evident from Fig. 4-6 that the time required for clearance of the road traffic once the train crosses the level crossings is about 13 mins. This delay may lead to 


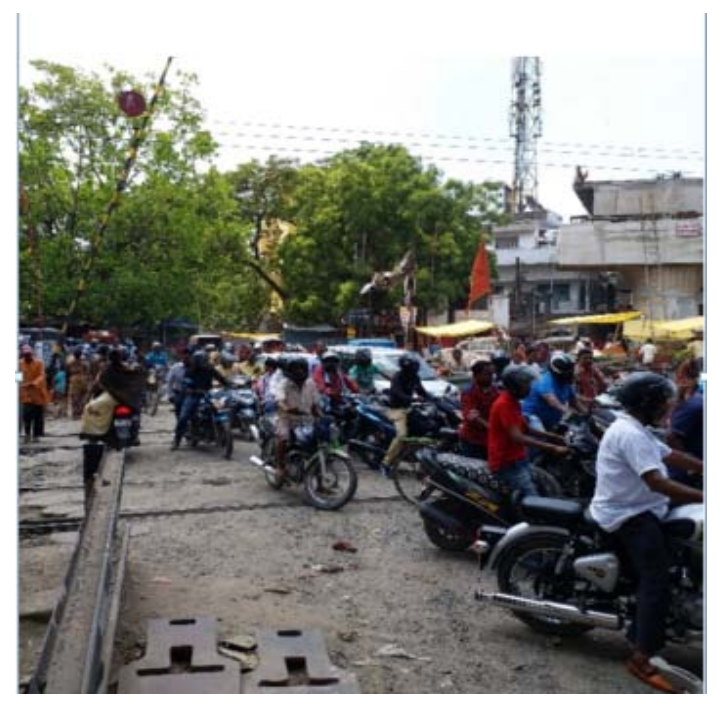

Fig. 2: Visuals of the level crossing in India under deliberation

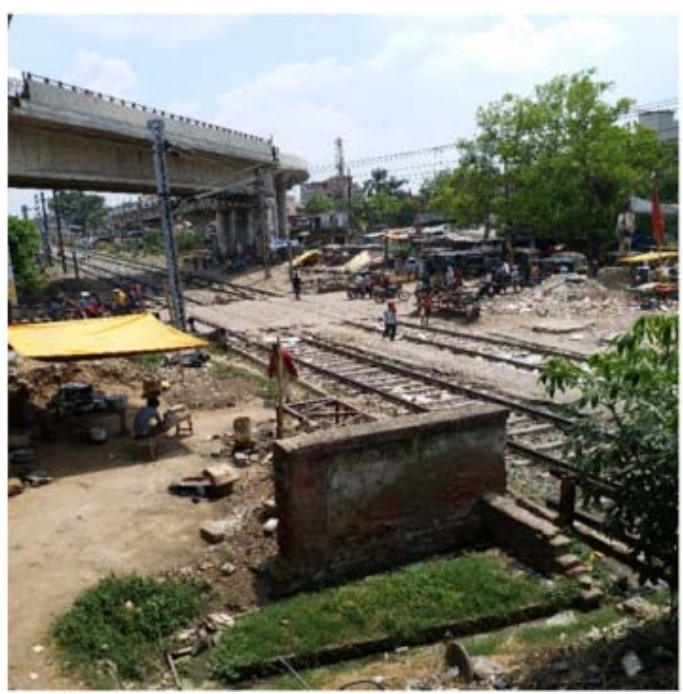

Fig. 3: Visuals of the level crossing in India under deliberation

Table 1: Average clearance time for road traffic at a level crossing

\begin{tabular}{lccc} 
Days & $\begin{array}{c}\text { Average } \\
\text { communication } \\
\text { time (min) }\end{array}$ & $\begin{array}{c}\text { Average time } \\
\text { for which gate } \\
\text { was closed (min) }\end{array}$ & $\begin{array}{c}\text { Average total } \\
\text { time for clearance } \\
\text { (min) }\end{array}$ \\
\hline 1 & 5.40 & 7.54 & 12.94 \\
2 & 5.20 & 7.80 & 13.00 \\
3 & 4.60 & 7.23 & 11.83 \\
4 & 4.94 & 8.20 & 13.14 \\
5 & 5.10 & 7.90 & 13.00 \\
6 & 6.30 & 8.40 & 14.70 \\
7 & 4.80 & 7.35 & 12.15 \\
8 & 5.90 & 7.45 & 13.35 \\
9 & 4.25 & 7.80 & 12.05 \\
10 & 5.35 & 7.63 & 12.98 \\
\hline
\end{tabular}

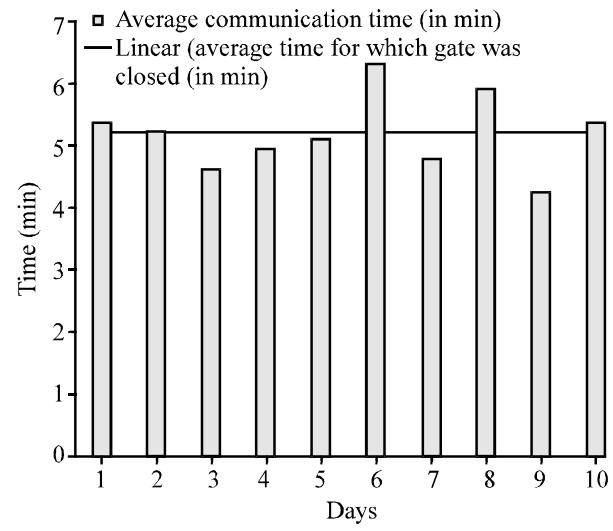

Fig. 4: Average communication time at the level crossing

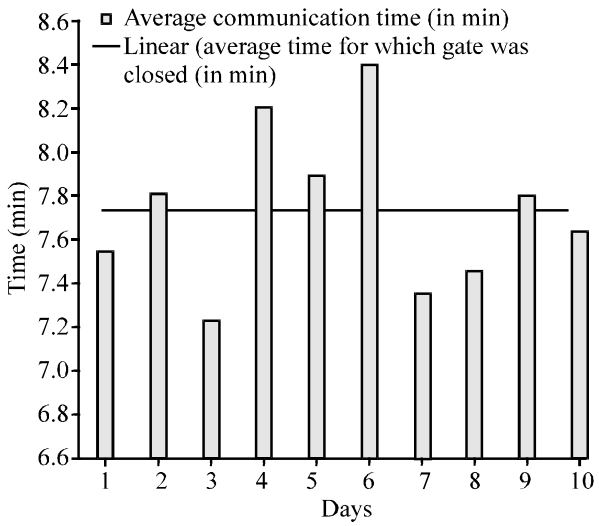

Fig. 5: Average closure time at the level crossing

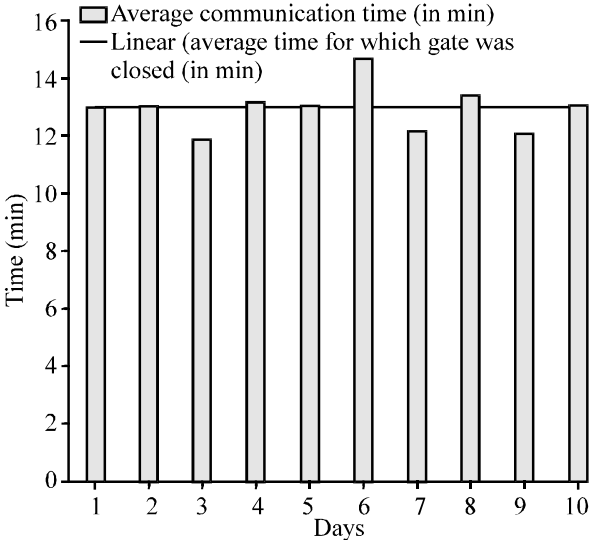

Fig. 6: Average clearance time for road traffic at the level crossing

congestion of the road traffic. Out of these 13 mins, approximately for $7.75 \mathrm{mins}$, the barrier remained closed and the communication regarding the closure or opening of barrier took approximately 5.25 mins. By usage of some automated techniques, the communication time pertaining to the closure and opening of the barrier may be decreased. The decrement of the overall wait time may 
lead to reduction in traffic congestion. Hence, it is better to go for automation of the level crossing instead of simply staffing it.

A comparative study of the various strategies and technologies used across the globe: In general, there are two types of level crossing protection systems: one based on manually operated signals and the other based on automatically operated signals. The level crossing staff based on the instructions received from the nearest railway station or the control centre operate the manually operated signals. In manually operated signals, the operation time lag is more as compared to the automatic ones. Besides, they are also prone to human errors. In automatic warning signals, the tracker circuit detect the presence of train in the vicinity and actuate the warning signals at the level crossings in the form of lights or horns. They have lesser time lag in communication and are comparatively error free. However, the automatic signalling systems are not immune from problems. Automatic warning signal s are not always fully effective. The flashing light may be problematic if the visibility of the level crossing with respect to the road is hindered. Similarly, in noisy environs the sound signals may not yield effective safety results.

One of the ways to reduce the mishaps at the level crossings is via management of the risk involved. The risk-based management has the ability to rank the level crossings within a jurisdiction. The identification of the possible causes of accidents can be identified using such management techniques. Besides this the proposal to overcome such problems may also be put forward. But such risk based systems are not sufficient to drop the rate of fatalities to zero. In the next section a conceptual frame work of the proposed automated methodology for gate mishap control at the level crossing has been proposed.

Proposed methodology: In India, most of the railway, tracks are two-way, so, two ultrasonic distance sensors (HCSR04) has been placed, one of each side of the railway track and the same configuration is repeated on the other side of the level crossing. When a train, approaches towards level crossing comes in front of the distance sensor, it emits short and high frequency sound pulses at regular intervals. These propagate in the air at the velocity of sound. If they strike an object, then they are reflected back as echo signals to the sensor which itself computes the distance to the target based on the time-span between emitting the signal and receiving the echo. Thus, ultrasonic distance sensor senses the arrival of train.

The electronic control unit of road vehicle also contains a CC3200 which will receive the signal

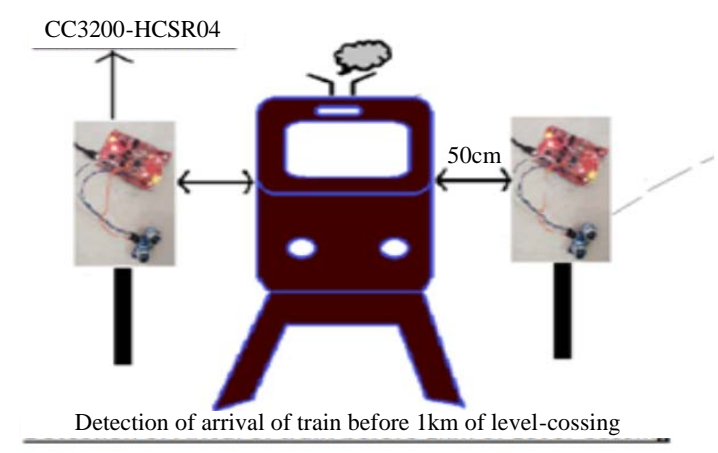

Fig. 7: Detection of arrival of train

transmitted by HC-SR04 over the Wi-Fi. Once ECU of road vehicles receives the signal of arrival of train, it comes in autonomous mode (Fig. 7). Driver cannot control the vehicle.

Now the auto fuel pump shut-off system is to be activated. According to this system, when ECU of vehicle receives the signal of arrival of train it immediately stops the supply of fuel to engine of vehicle. For the demonstration purpose a red LED is connected to the GPIO (General Purpose Input/Output pin) of CC3200 which glows when fuel pump shut-off system is activated. So, red LED is used an indicator for auto fuel pump shut-off system. It continues glowing till the ECU of vehicle does not receives the complete departure of train.

After the activation of auto fuel pump shut-off system, train does not stop immediately due to its momentum. So, the auto gear changing mechanism first slows down the speed of vehicle, so that, brake can safely be applied on the road vehicle. Wheels of the vehicle used for demonstration are directly connected to DC motors. Motors used in demo vehicle have $100 \mathrm{rpm}$. Motion of these motors are controlled by using L293D-motor driver IC. Operating voltage of this IC is $4.5-36 \mathrm{~V}$ DC. Motors are connected to the inputs of L293D and output of this IC is connected to the GPIO of CC3200. So, after activation of auto fuel pump shut-off system, All the GPIO of CC3200 corresponding to the output of motor driver IC becomes LOW and thus, vehicle completely stops.

Now, the road vehicle stays on the road and wait till the electronic control unit of vehicle does not receives the complete departure of train from the level-crossing. There is another set of ultrasonic distance sensors on the other side of the level-crossing. When train comes in front of the distance sensor after crossing the level-crossing, again the CC3200 connected to distance sensor sends signal of complete departure of 


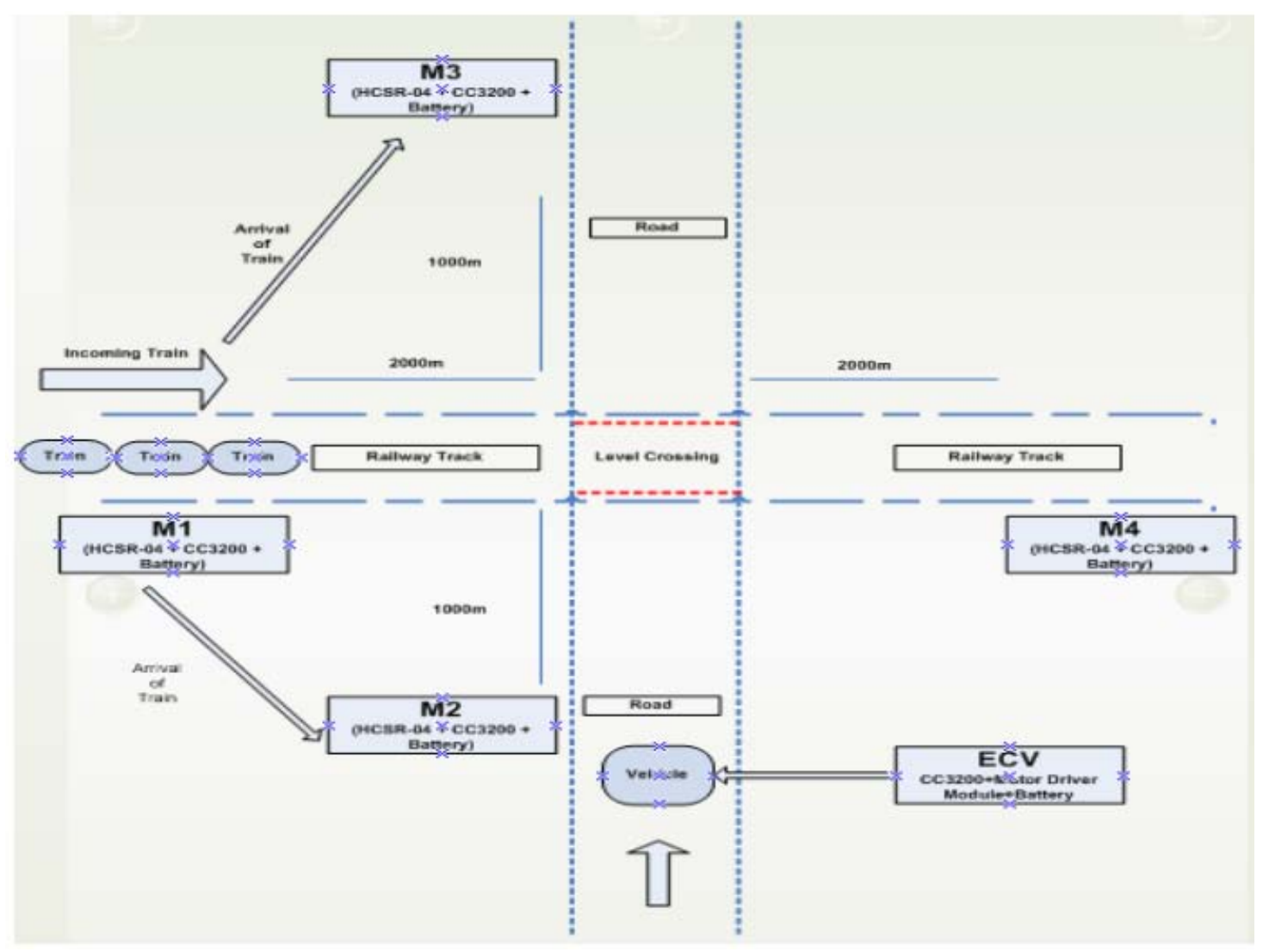

Fig. 8: Schematic representation of the proposed safety layout at the level crossing

train from the level-crossing over the WiFi to the ECU of road vehicles. This job is similar to the broadcasting of the information of arrival of train (Fig. 8).

When the electronic control unit of road vehicle receives the information of departure of train from the level-crossing, it deactivates the auto fuel pump shut-off system and starts supply of fuel to the engine of vehicle. Deactivation of auto fuel cut system is indicated by glowing the green LED connected to the GPIO of CC3200. Now, the GPIO of motors becomes high. Complete controlling mechanism of vehicle comes under the driver of the vehicle. Driver can control the vehicle manually.

\section{CONCLUSION}

The study presented a comprehensive survey of the existing strategies adopted for improving the security and safety at the level crossings. It may be concluded that the strategies adopted worldwide are situation specific. However, for the ease of understanding the strategies may be classified as technology based strategies, anthropological issue based strategies and risk management based strategies. The study also discussed the Indian scenario in particular. A case study of the level crossing in the Eastern part of India was considered and the effect of staffing the level crossing was studied. It was concluded from the study that the manned level crossings may lead to congestion in road traffic and hence, it is better to adopt automation based barrier functioning at the level crossings. A comparative study of the prevalent worldwide techniques used for safety at level crossings are also discussed in the study. The study accomplishes with the discussion on the proposed conceptual framework of the methodology which may be engaged to improve the safety scenario at the level crossings. the conclusions drawn from the work may be enlisted in the following points.

A new approach for improving safety at railway crossing in Indian Railway has been suggested. This technology carries the potential to lower the number of accidents by alerting people of the danger well before it approaches.

A system for improving safety at railway level crossing, particularly suitable for Indian Railway has been developed. The system is based on modern technology and psychology of the road users. Software for the 
complete operation of the system has been developed besides a working model. This is expected to give timely warning and create an environment of alertness and danger to the road users. This will reduce the requirement of manpower and hence, the recurring expenditure.

\section{REFERENCES}

Anandarao, S. and C.D. Martland, 1998. Level crossing safety on East Japan Railway Company: Application of probabilistic risk assessment techniques. Transp., 25: $265-286$.

Anjali, M. and A. Geetha, 2017. Sensor based alert system at unmanned level crossing. J. Environ. Nanotechnol, 6: 05-09.

Anonymous, 2012. Australian rail safety occurrence data: 1 July 2002 to 30 June 2012. Australian Transport Safety Bureau, Canberra, Australia. https://www. atsb.gov.au/media/4042317/rr2012010_final.pdf

Chouhan, S., 2014. Railway anti-collision system using DSLR sensor. Intl. J. Eng. Sci. Res. Technol., 3: 1199-1202.

Da Costa, I.G. and T.V.N. Pereira, 2018. Control arrangement for a railroad level crossing. US. Pat. Appl., 1: 1-10.

Dewangan, A.K., M. Gupta and P. Patel, 2012. Automation of railway gate control using microcontroller. Intl. J. Eng. Res. Technol., 1: 1-8.

Farr, E.H., 1987. Summary of DOT rail-highway crossing resource allocation procedure-revised. Master Thesis, U.S. Department of Transportation, Volpe National Transportation Systems Center, Cambridge, Massachusetts.

Fries, J. and W. Shields, 2018. System and method for controlling a level crossing. US. Pat. Appl., 1: 1-7.

Garcia-Dominguez, J.J., J. Urena-Urena, A. HernandezAlonso, M. Mazo-Quintas and J.F. Vazquez et al., 2008. Multi-sensory system for obstacle detection on railways. Proceedings of the 2008 IEEE International Conference on Instrumentation and Measurement Technology, May 12-15, 2008, IEEE, Victoria, Canada, ISBN:978-1 -4244-1540-3, pp: 2091-2096.

Govoni, M., F. Guidi, E.M. Vitucci, V. Degli Esposti and G. Tartarini et al., 2015. Ultra-wide bandwidth systems for the surveillance of railway crossing areas. IEEE. Commun. Mag., 53: 117-123.

Jadhav, R., H. Patil and M.S. Wagh, 2017. Automatic railway gate control system using RFID with high alerting system. Intl. Res. J. Eng. Technol., 4: 2700-2702.
Jeong, Y.S., C.S. Nam, H.J. Jeong and D.R. Shin, 2008. Train auto control system based on OSGi. Proceedings of the 10th International Conference on Advanced Communication Technology (ICACT) Vol. 1, February 17-20, 2008, IEEE, Gangwon-Do, South Korea, ISBN:978-89-5519-135-6, pp: 276-279.

Kim, G., H.Y. Choi, J.H. Baek and Y.K. Kim, 2014. Field test of safety monitoring system for railroad level crossings using laser scanner. Proceedings of the 2014 International Conference on Information and Communication Technology Convergence (ICTC), October 22-24, 2014, IEEE, Busan, South Korea, ISBN:978-1-4799-6786-5, pp: 657-658.

Kim, G., J. Baek, H. Jo, K. Lee and J. Lee, 2012. Design of safety equipment for railroad level crossings using laser range finder. Proceedings of the 9th International Conference on Fuzzy Systems and Knowledge Discovery, May 29-31, 2012, Sichuan, China, pp: 2909-2913.

Kumar, A. and P.K. Sinha, 2008. Human error control in railways. Jordan J. Mech. Ind. Eng., 2: 183-190.

Kumar, A. and R. Singh, 2014. Automatic collision detection for an autonomous robot using proximity sensing technology on an AVR hardware platform. Intl. J. Res. Eng. Technol., 3: 214-217.

Lakshmi, P. and S.R. Kumar, 2015. Accident detection system in railway by using wireless networks. Intl. J. Adv. Technol. Innovative Res., 7: 1-6.

Larue, G.S. and C. Wullems, 2017. A new method for evaluating driver behavior and interventions for passive railway level crossings with pneumatic tubes. J. Transp. Saf. Secur., 1: 1-17.

Larue, G.S., A. Rakotonirainy, N.L. Haworth and M. Darvell, 2015. Assessing driver acceptance of intelligent transport systems in the context of railway level crossings. Transp. Res. Part F. Traffic Psychology Behav., 30: 1-13.

Larue, G.S., R. Blackman and J. Freeman, 2018. Impact of waiting times on risky driver behaviour at railway level crossings. Proceedings of the International Congress on International Ergonomics Association, August 26-30, 2018, Springer, Cham, Switzerland, ISBN:978-3-319-96073-9, pp: 62-69.

Li, C.W., C.C. Chu, H.W. Wu and H.C. Wang, 2017. A study on intelligent level crossing safety control system. J. Comput., 28: 96-102.

Liu, Q., T. Wang and R.R. Souleyrette, 2017. A 3D evaluation method for rail-highway hump crossings. Comput. Aided Civ. Infrastruct. Eng., 32: 124-137.

Mapari, E.N., S.M. Imran, N. Ashraf and S. Chaudhari, 2016. Android based controller for railway gate crossing. Imperial J. Interdiscip. Res., 2: 352-355. 
Marquez, F.P.G., D.J. Pedregal and C. Roberts, 2015. New methods for the condition monitoring of level crossings. Intl. J. Syst. Sci., 46: 878-884.

Masek, J., P. Kolarovszki and J. Camaj, 2016. Application of RFID technology in railway transport services and logistics chains. Procedia Eng., 134: 231-236.

Nelson-Furnell, P., 2012. The Australian level crossing assessment model equipping and engaging crossing stakeholders. Proceedings of the 12th International Symposium on Global Level Crossing and Trespass, October 8-10, 2012, University International Club (UIC), London, UK., pp: 7-12.

Pattanaik, L.N. and G. Yadav, 2015. Decision support model for automated railway level crossing system using fuzzy logic control. Procedia Comput. Sci., 48: 73-76.

Potdar, A.S., S. Shinde, P.H. Nikam and M. Kurumkar, 2017. Wireless sensor network for real time monitoring and controlling of railway accidents. Proceedings of the 2017 International Conference on Trends in Electronics and Informatics (ICEI), May 11-12, 2017, IEEE, Tirunelveli, India, ISBN: 978-1-5090-4258-6, pp: 190-197.
Punekar, N.S. and A.A. Raut, 2013. Improving railway safety with obstacle detection and tracking system using GPS-GSM model. Intl. J. Sci. Eng. Res., 4: 282-288.

Pwint, H.N.Y., Z.M. Tun and H.M. Tun, 2014. Automatic railway gate control system using microcontroller. Intl. J. Sci. Eng. Technol. Res., 3: 1547-1551.

Sreelakshmi, K.U., A. Thomas, K.B. Krishnapriya and V. John, 2017. Railway level crossing gate control and measurement system for railway track condition monitoring. Intl. J. Emerging Technol. Innovative Res., 4: 101-110.

Tastimur, C., M. Karakose and E. Akin, 2017. Image processing based level crossing detection and foreign objects recognition approach in railways. Intl. J. Appl. Math. Electron. Comput., 5: 19-23.

Tey, L.S., L. Ferreira and A. Wallace, 2011. Measuring driver responses at railway level crossings. Accid. Anal. Prevent., 43: 2134-21 41.

Xishi, W., N. Bin and C. Yinhang, 1992. A new microprocessor based approach to an automatic control system for railway safety. Proceedings of the IEEE International Symposium on Industrial Electronics, May 25-29, 1992, IEEE, Xian, China, pp: 842-843. 